Keywords: Rotary microfilter, backpressure, nuclear waste, SCIX

Retention: Permanent

\title{
Backpressure Testing of Rotary Microfilter Disks
}

\author{
Mark D. Fowley
}

David T. Herman

April 2011

Savannah River National Laboratory Savannah River Nuclear Solutions Aiken, SC 29808

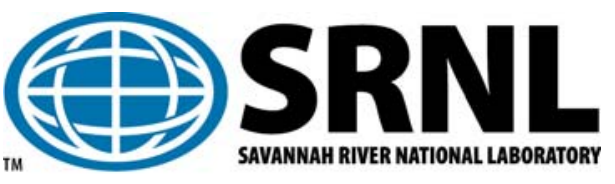


SRNL-STI-2010-00790

Revision 0

\section{DISCLAIMER}

This work was prepared under an agreement with and funded by the U.S. Government. Neither the U.S. Government or its employees, nor any of its contractors, subcontractors or their employees, makes any express or implied:

1. warranty or assumes any legal liability for the accuracy, completeness, or for the use or results of such use of any information, product, or process disclosed; or

2. representation that such use or results of such use would not infringe privately owned rights; or

3. endorsement or recommendation of any specifically identified commercial product, process, or service.

Any views and opinions of authors expressed in this work do not necessarily state or reflect those of the United States Government, or its contractors, or subcontractors.

\section{Printed in the United States of America \\ Prepared for \\ U.S. Department of Energy}




\section{REVIEWS AND APPROVALS}

AUTHORS:

M. D. Fowley, Process Engineering Technology Date

D. T. Herman, Advanced Characterization and Processing Date

REVIEWER:

J. L. Steimke, Process Engineering Technology

Date

APPROVALS:

B. J. Giddings, Manager

Date

Process Engineering Technology

F. M Pennebaker, Manager

Date

Advanced Characterization and Processing

S. L. Marra, Manager

Date

Environmental \& Chemical Process Technology Research Programs 


\section{EXECUTIVE SUMMARY}

The Savannah River National Laboratory has performed tests with SpinTek ${ }^{\mathrm{TM}}$ rotary microfilter disks to study the physical effects of backpressure on the disks and to determine the maximum allowable backpressure. The disks were made from $316 \mathrm{~L}$ stainless steel and used the Pall Corporation PMM050 0.5 micron filter membrane. Backpressure (or reverse flow) was incrementally applied to the disks until membrane failure or maximum application of testing pressure. Failure was defined as the inability to filter effectively at the nominal filter pore size, and effective filtration was determined by turbidity measurements of filtrate that was produced by applying forward-pressure to the disks while submerged in a representative simulant. Tank 8F simulated sludge was the representative simulant used for the forward-pressure test.

Two rotary disks were available for testing and both had backpressure applied during the testing program. The filter membranes of both disks were permanently deformed during testing but retained the ability to effectively filter the simulated sludge when stationary. The amount of backpressure that caused the deformation was inconsistent between the two disks. Disk 1 showed permanent deformation after 45 psig, and was eventually backpressured to 75 psig with little additional deformation. The deformation was not great enough to allow contact with the stationary promoters. Disk 2 deformed at 5 psig where it appeared to contact the promoters, which would disable a rotating microfilter. Forward-pressure testing of both disks revealed that the turbidity readings remained relatively constant from before and after backpressure testing, indicating that the effectiveness of the filter when stationary was not affected by the deformation.

The results indicate that either engineering controls must be put into place to prevent rotation of the disks during a backpressure event or the rotary disks must be redesigned to prevent deformation during backpressuring. 


\section{TABLE OF CONTENTS}

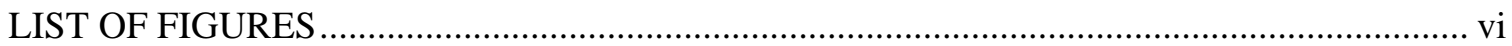

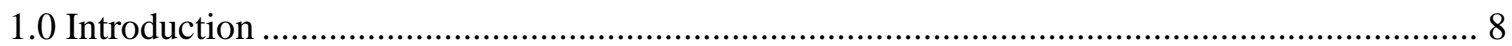

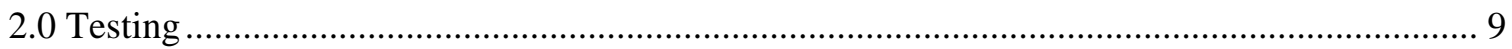

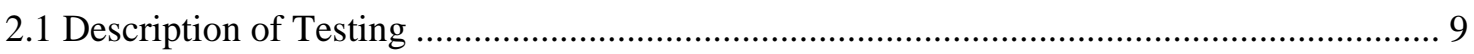

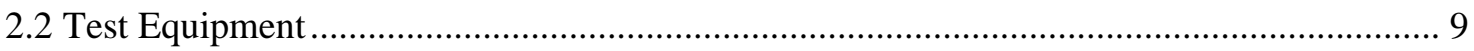

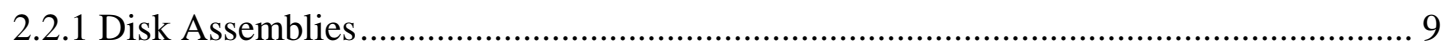

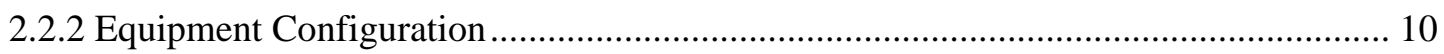

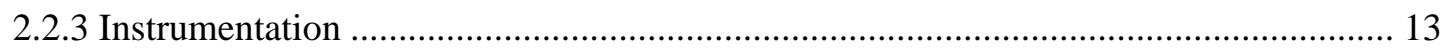

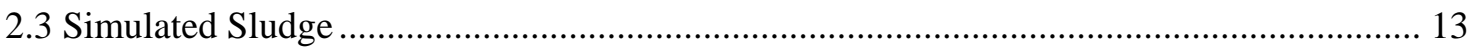

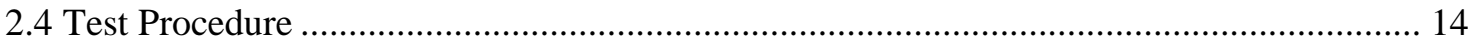

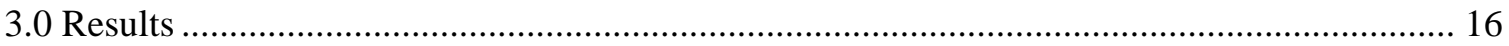

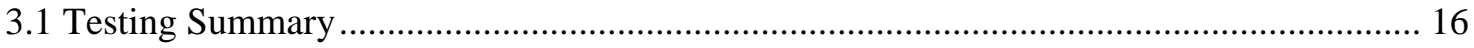

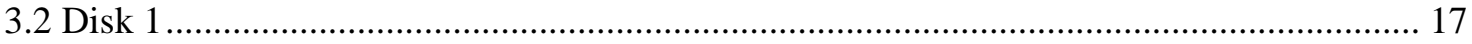

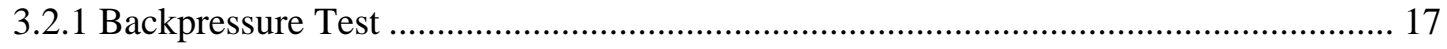

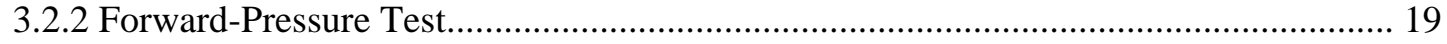

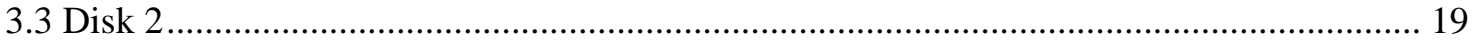

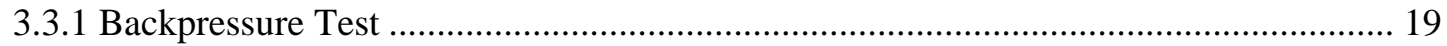

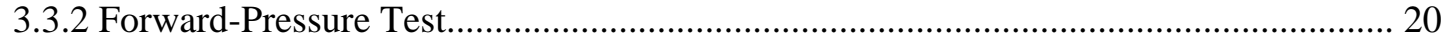

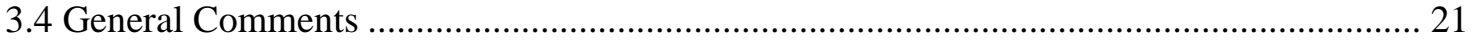

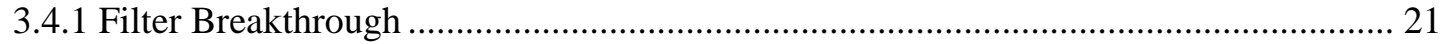

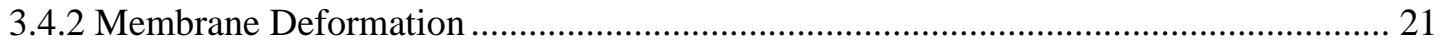

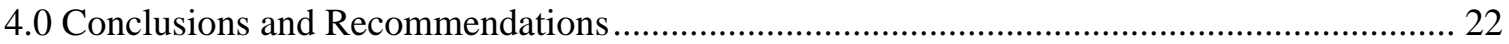

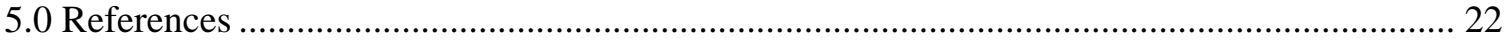




\section{LIST OF TABLES}

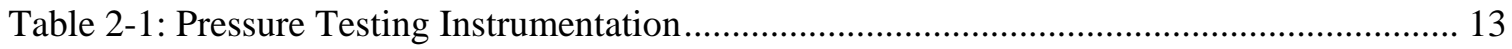

Table 2-2: Expected Anion/Cation Content of Sludge Feed Simulants ...................................... 13

\section{LIST OF FIGURES}

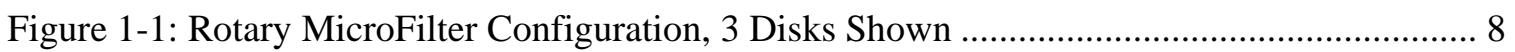

Figure 1-2: 25 Disk Rotary MicroFilter Assembly .................................................................. 9

Figure 2-1: Hub of SpinTek Stainless Steel Rotary MicroFilter Disk....................................... 10

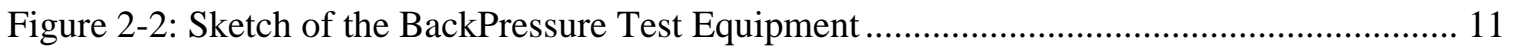

Figure 2-3: Sketch of the Forward-Pressure Test Equipment …................................................. 12

Figure 2-4: Hub Fitting for Pressure Tests. Assembly View, Outer View \& Inner View (with O-

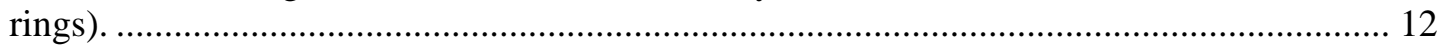

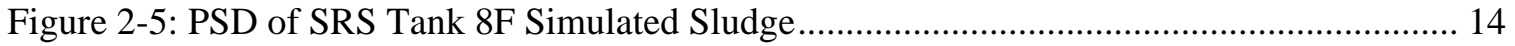

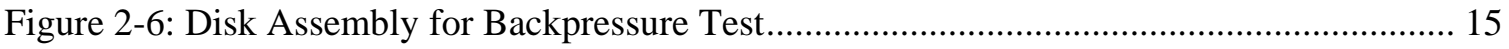

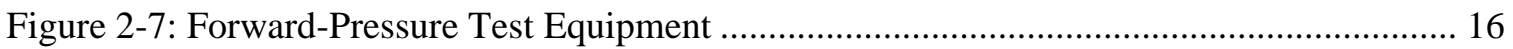

Figure 3-1: Disk 1 during the Backpressure Test ......................................................................... 17

Figure 3-2: Disk 1 After 40 psig Backpressure .......................................................................... 18

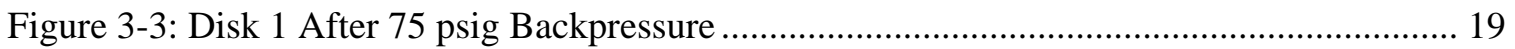

Figure 3-4: Deformation of Disk 2 Membrane........................................................................... 20

Figure 3-5: Vials of Filtrate (left) and Turbidity Standards (0.02, 10.0 \& 1000 NTU)................ 20

Figure 3-6: Wrinkles in the Front and Back Membranes of Disk 2 ........................................... 21 


\section{LIST OF ABBREVIATIONS}

$\begin{array}{ll}\text { DI } & \text { Deionized } \\ \text { DOE } & \text { Department of Energy } \\ \text { EDL } & \text { Engineering Development Laboratory } \\ \text { FS } & \text { Full Scale } \\ \text { Hg } & \text { Mercury } \\ \text { ID } & \text { Inner Diameter } \\ \text { in } & \text { inch } \\ \text { MAWP } & \text { Maximum Allowable Working Pressure } \\ \text { ml } & \text { Milliliters } \\ \text { NTU } & \text { Nephelometric Turbidity Unit } \\ \text { OD } & \text { Outer Diameter } \\ \text { psia } & \text { Pounds per square inch, absolute } \\ \text { psid } & \text { Pounds per square inch differential } \\ \text { psig } & \text { Pounds per square inch, gauge } \\ \text { RCRA } & \text { Resource Conservation and Recovery Act } \\ \text { RDG } & \text { Reading } \\ \text { RMF } & \text { Rotary MicroFilter } \\ \text { SCFM } & \text { Standard Cubic Feet per Minute } \\ \text { SRNL } & \text { Savannah River National Laboratory } \\ \text { SRS } & \text { Savannah River Site }\end{array}$




\subsection{Introduction}

The Savannah River National Laboratory (SRNL), under the Department of Energy (DOE) Office of Environmental Management (EM), is modifying and testing the SpinTek ${ }^{\mathrm{TM}}$ rotary microfilter (RMF) for radioactive filtration service in the Department of Energy (DOE) complex. The RMF has been shown to improve filtration throughput when compared to other conventional methods such as cross-flow filtration [1,2]. A concern with the RMF was that backpressure, or reverse flow through the disk, would damage the filter membranes. Reverse flow might happen as a result of an inadvertent valve alignment during flushing. Testing was completed in the Engineering Development Laboratory (EDL) located in SRNL to study the physical effects of backpressure as well as to determine the maximum allowable back-pressure for RMF disks [3].

The RMF disks tested at the EDL were manufactured by SpinTek ${ }^{\mathrm{TM}}$ Filtration and used a Pall Corporation PMM050 filter membrane (0.5 micron nominal pore size) made from 316L stainless steel. Early versions of the RMF disks were made from synthetic materials that were incompatible with caustic solutions and radioactive service as well as being susceptible to delaminating when subjected to backpressure. Figure 1-1 shows the essential components of the RMF; 3 rotating disks and 3 stationary turbulence promoters (or shear elements) are shown. Figure 1-2 show the assembly view of a 25 disk RMF proposed for use at the Savannah River Site (SRS) and at the Hanford Facility.

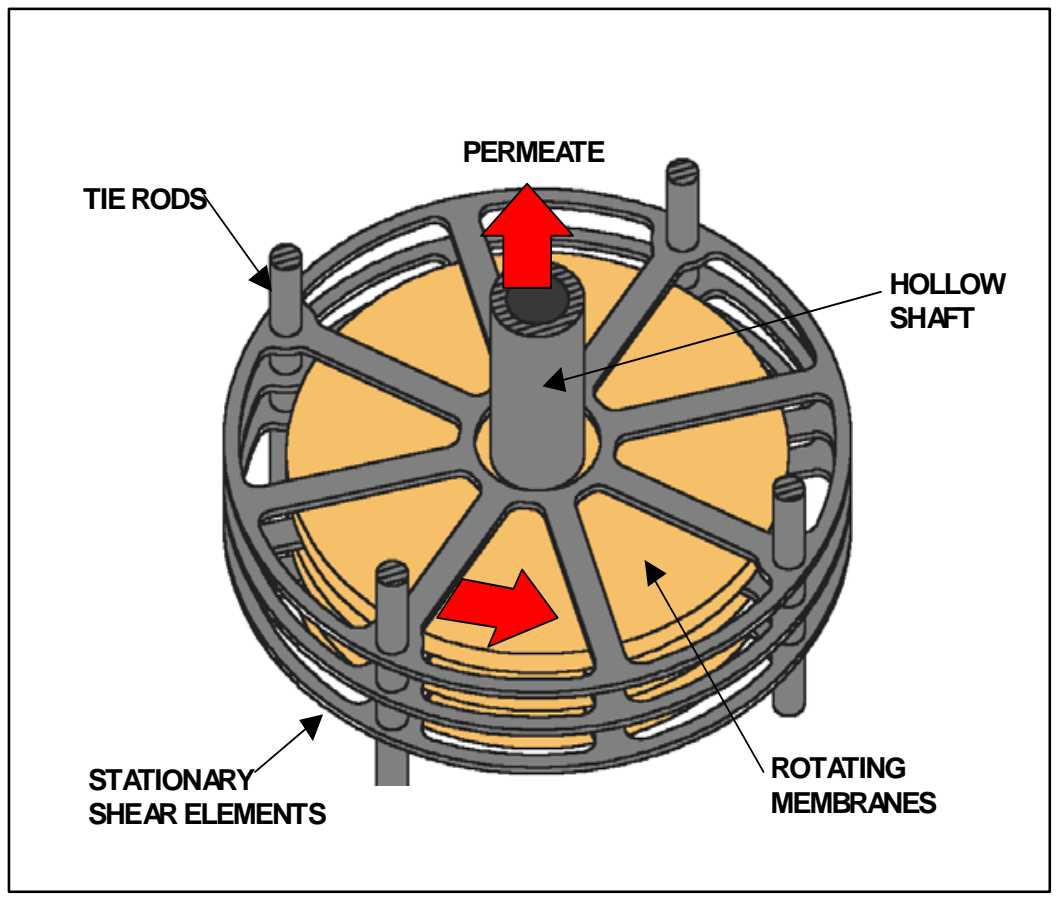

Figure 1-1: Rotary MicroFilter Configuration, 3 Disks Shown 


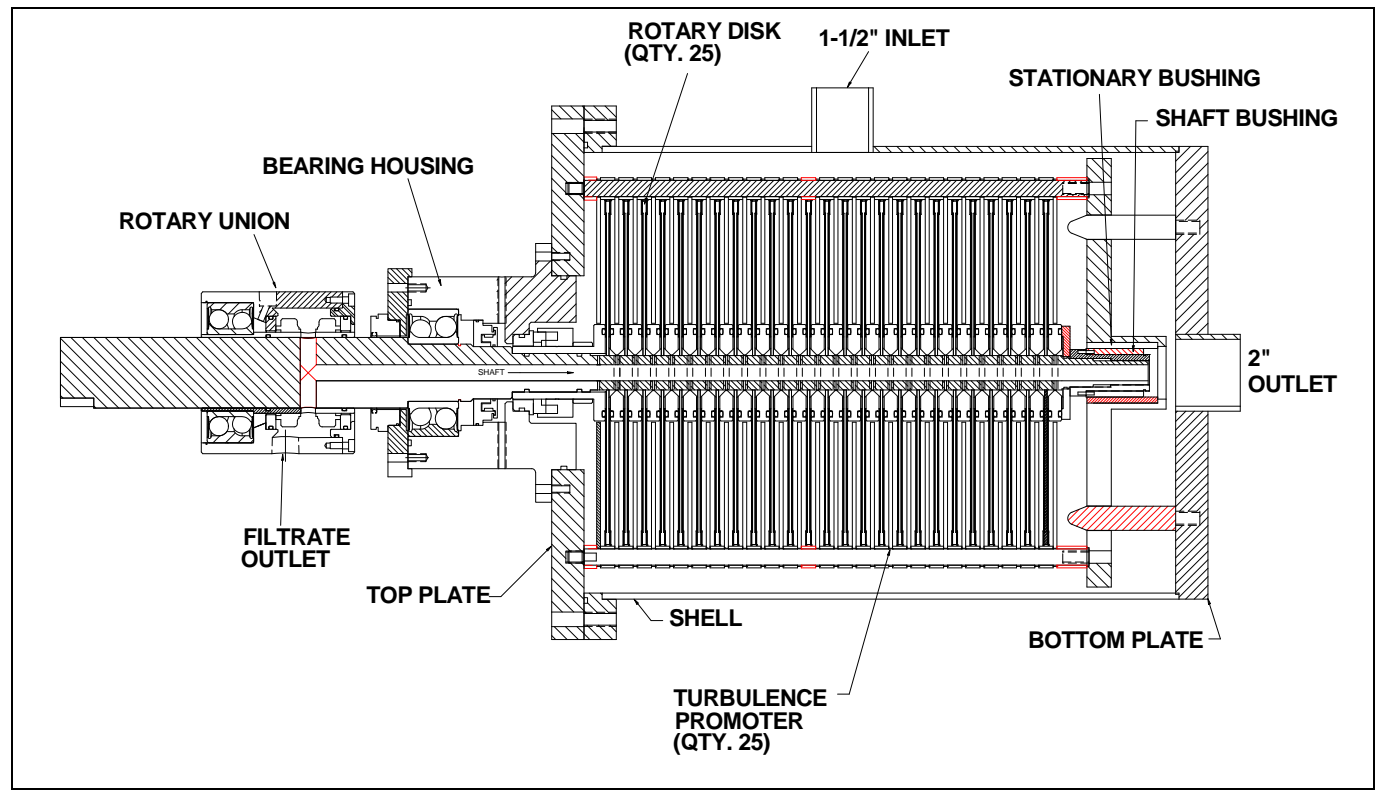

Figure 1-2: 25 Disk Rotary MicroFilter Assembly

\subsection{Testing}

\subsection{Description of Testing}

The purpose of the testing discussed in this report was to determine the allowable backpressure for RMF disks as well as study the physical effects of backpressure on RMF disks made with the Pall PMM050 membrane. This was accomplished by pressurizing the disks in the reverse flow direction (backpressure) until the test limit was reached or until membrane failure occurred. Backpressure was applied to the disks with air while submerged in deionized (DI) water. This method provided a visual representation of membrane integrity via bubble flow patterns. Membrane failure was defined as the inability to filter effectively at the nominal filter pore size. Effective filtration was determined by turbidity measurements of filtrate that was produced by applying forward-pressure to the disks while submerged in a representative simulant. The representative simulant was Tank 8F simulated sludge produced for SRNL by Optima Chemical [4].

Two disks were tested. Disk 1 was tested primarily to determine approximate levels of backpressure where membrane failure occurred. These levels were then used to define the strategy for testing the Disk 2; a strategy that would better define and quantify the mode of failure.

\subsection{Test Equipment}

Separate test equipment was used for the backpressure and forward-pressure tests. That equipment is discussed in the following sections.

\subsubsection{Disk Assemblies}

The rotary disks were constructed from stainless steel, and formed in a sandwich-like configuration (Figure 2-1). The center was a solid core, approximately 10-3/4 inches in diameter and 0.125 inches thick, with a notched hole in the middle to accommodate the hollow shaft. On both sides of the core was a large-mesh screen that provided the flow path for the filtrate to the 
hollow shaft, and on top of each screen was the Pall Corporation PMM050 0.5 micron nominal pore size filter, which was only 0.007 inches thick. The stainless steel membranes were made by adhering powdered stainless steel to a woven wire mesh. The effective filter area of each disk was $0.98 \mathrm{ft}^{2}$ (value includes both sides of the disk). The membrane was seal-welded to the solid core at the outer perimeter but was not welded or similarly affixed to the core at the hub. The membrane was sealed at the hub by o-rings. In the 25-disk RMF the o-rings are in the shaft assembly; in the EDL disk assembly the o-rings were in a special hub fitting (reference section 2.2.2).

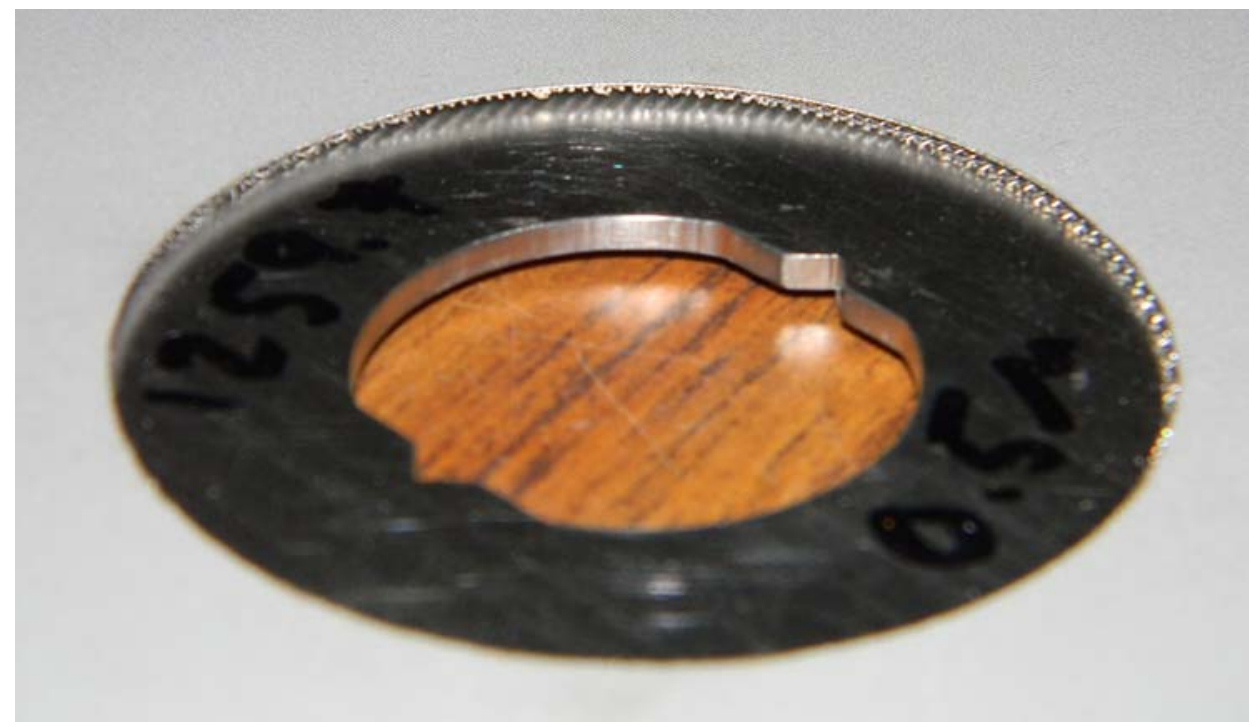

\section{Figure 2-1: Hub of SpinTek Stainless Steel Rotary MicroFilter Disk}

The EDL disk assembly had two turbulence promoters (or stationary shear elements, reference Figure 1-1and Figure 2-6) on either side of the rotary disk. The disk and two promoters were held together by four bolts at the periphery of the turbulence promoters. A pair of Teflon spacers ( 0.125 inches thick), located on each bolt, maintained a 0.125 inch spacing between the surfaces of the disk and the promoters. The disk was radially centered in the promoters by the hub fitting, which fit snugly in the inner diameter (ID) of each promoter. The hub fitting itself was centered on the disk during assembly and centrality was verified by measurement from the hub outer diameter (OD) to the disk OD at four places. The clearance between the filter membranes and the turbulence promoters from the hub to the OD was approximately 0.125 inches.

\subsubsection{Equipment Configuration}

The two test configurations for the backpressure and forward-pressure tests are depicted in Figure 2-2 and Figure 2-3.

For the backpressure test the disk assembly was submerged in a clear tank of DI water to observe the air flow from the disk membranes. Air was provided by the house air supply in the EDL. A pressure regulator was used to maintain a steady supply pressure and assure that maximum allowable working pressure (MAWP) of the lowest rated piece of equipment in the line was not exceeded. An air dryer provided clean dry air to the disk. A throttle valve downstream of the air dryer set the flow rate and provided pressure on the disk membranes. An isolation valve between the pressure regulator and house air supply provided pressure source isolation for equipment maintenance or replacement. A lid was placed over the open top tank to contain splashing water. 
A stand was constructed from various pieces of laboratory equipment to position the disk assembly vertically in the tank. The vertical position enabled balanced air flow on either side of the disk.

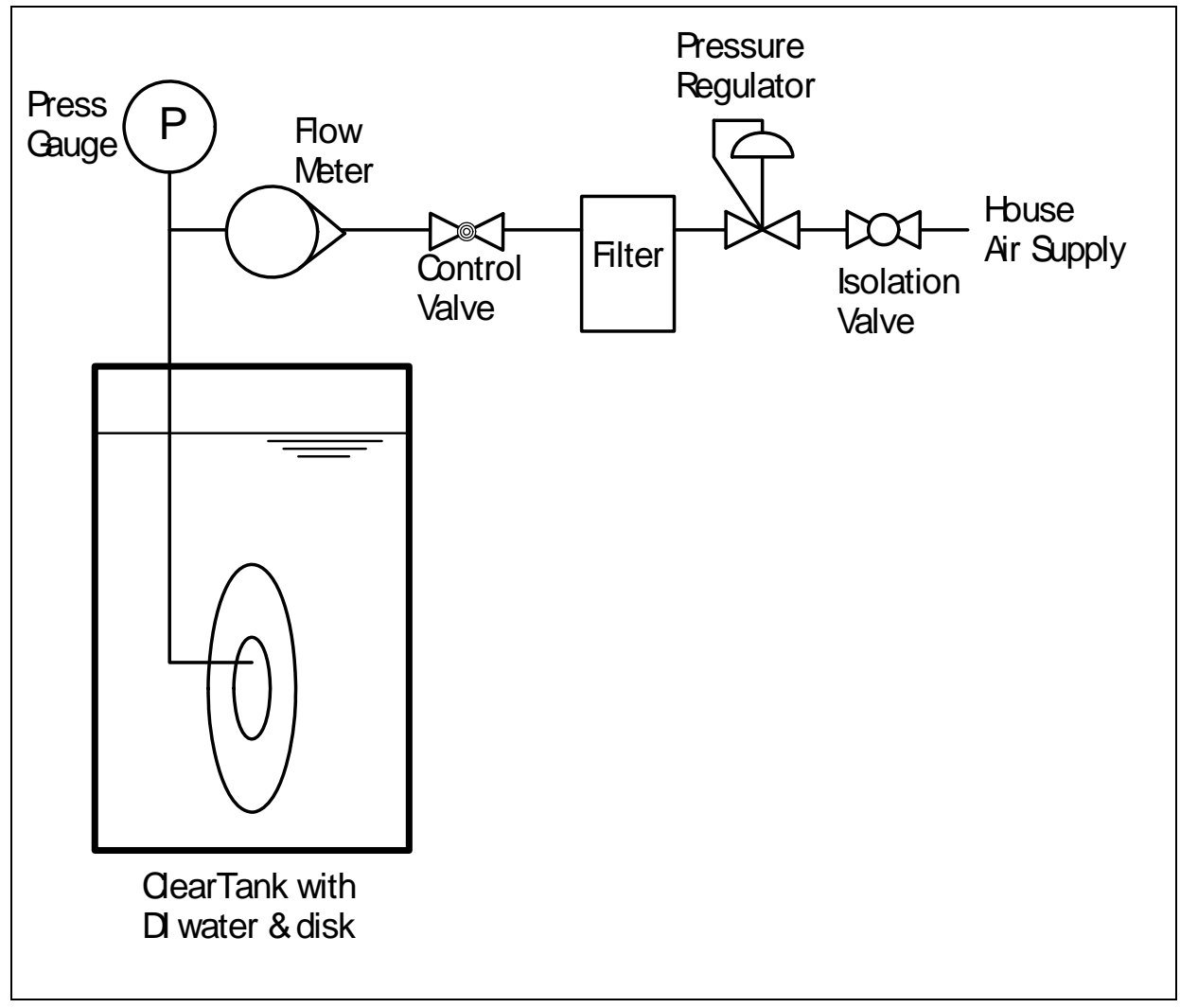

Figure 2-2: Sketch of the BackPressure Test Equipment

For the forward-pressure test the disk was submerged in simulated sludge to extract filtrate through the filter membranes. The turbidity of the filtrate was measured to quantify the efficiency of the RMF. A standard laboratory vacuum pump was used to pull filtrate through the membranes in the forward direction. A container in between the pump and the disk collected the filtrate for turbidity measurement. A vent valve at the vacuum pump was used to regulate the vacuum on the disk and an isolation valve in between the pump and the vacuum container provided isolation for the container and the disk, if desired. The simulated sludge was contained in a shallow tub where the disk was placed in the horizontal position. The position of the disk was deemed inconsequential for extracting filtrate; therefore, the horizontal position was chosen to minimize the amount of simulated sludge required. 


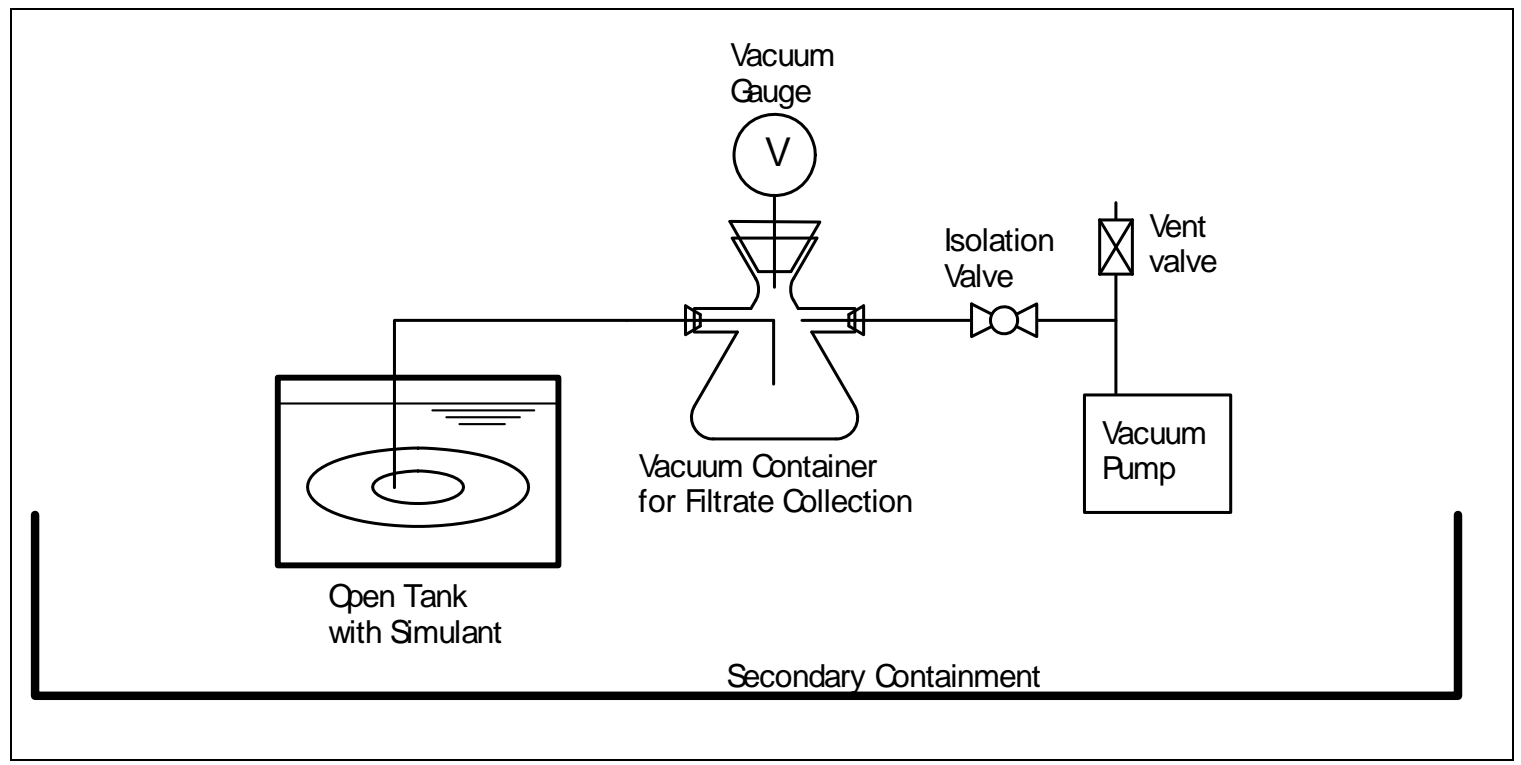

Figure 2-3: Sketch of the Forward-Pressure Test Equipment

In both the backpressure and forward-pressure test a special hub fitting was used to apply pressure and vacuum to the RMF (see Figure 2-4). The hub fitting was constructed of two separate pieces that were mechanically joined by a threaded stub in the center. Each piece contained an o-ring on the inner surface to provide a seal on the membrane surface. One side of the fitting contained a Swagelok ${ }^{\circledR}$ connector for the pressure or vacuum line.
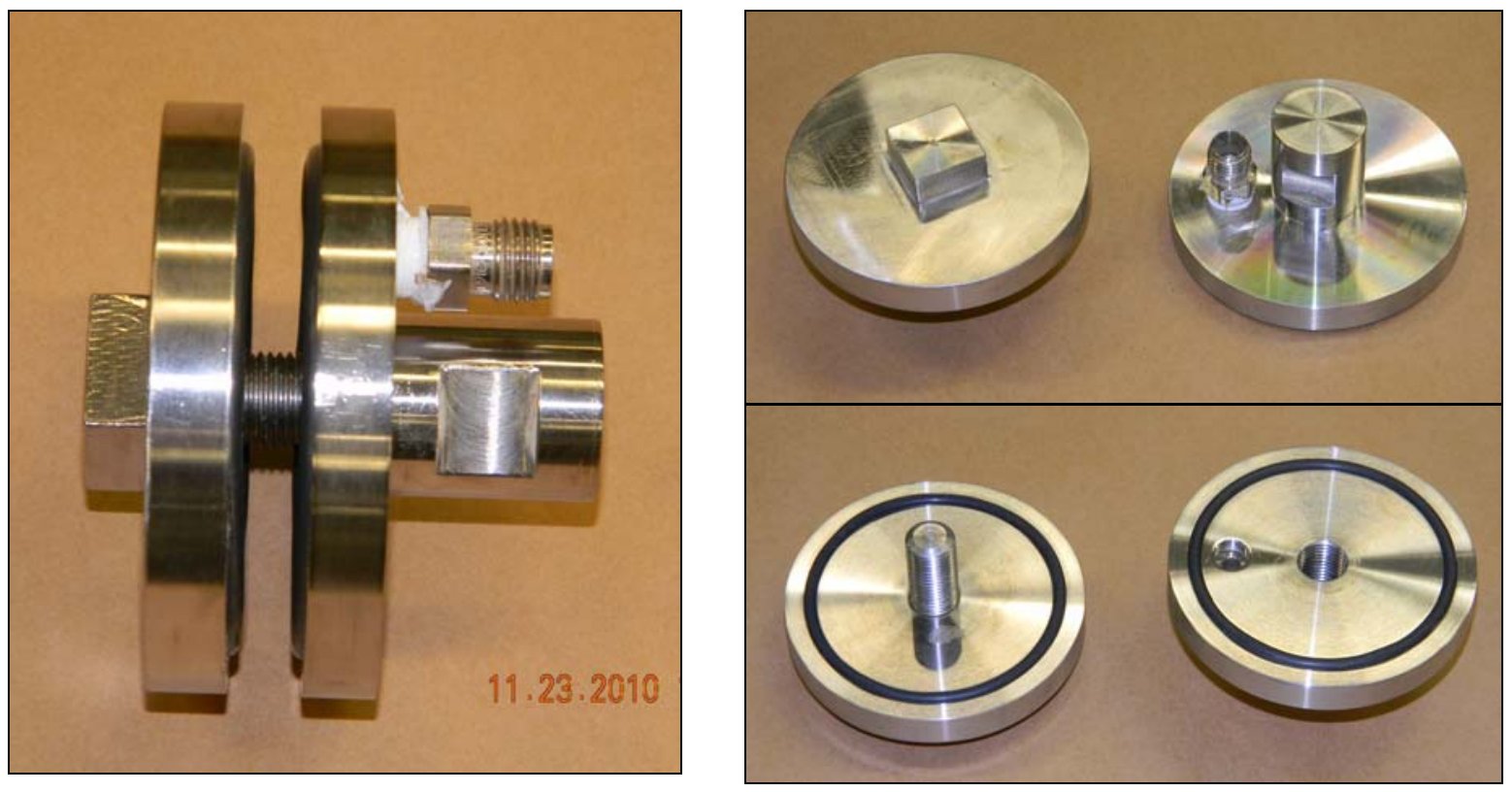

Figure 2-4: Hub Fitting for Pressure Tests. Assembly View, Outer View \& Inner View (with O-rings). 


\subsubsection{Instrumentation}

A rotameter was used to measure air flow to each disk during the backpressure test. A pressure gauge was used to measure the pressure applied to the disk during the backpressure test and a vacuum gauge was used to measure vacuum applied to the disk during the forward-pressure test. A bench-top turbidity meter was used to measure the turbidity of the filtrate extracted from each disk during the forward-pressure test. The accuracy of the turbidity meter was verified by vendor supplied turbidity standards before each measurement or series of measurements. Table 2-1 lists the instrumentation used during the testing.

Table 2-1: Pressure Testing Instrumentation

\begin{tabular}{|c|c|c|c|c|}
\hline Test & Description & M\&TE Number & Range & Tolerance \\
\hline Backpressure & Rotameter & $3-4943^{1}$ & $47.5 \mathrm{scfm}$ & $\pm 3 \% \mathrm{FS}^{1}$ \\
\hline Backpressure & Pressure Gauge & TR-40001 & 0-100 psig & $\pm 3 \% \mathrm{FS}$ \\
\hline Fwd-Pressure & Vacuum Gauge & TR-40002 & $0-30$ in $\mathrm{Hg}$ vac & \pm 1 in $\mathrm{Hg}$ vac \\
\hline $\begin{array}{l}\text { Backpressure } \\
\text { Fwd-Pressure }\end{array}$ & Turbidity Meter & $\mathrm{N} / \mathrm{A}^{2}$ & 0-1000 NTU & $\begin{array}{l}\text { Greater of } \pm 2 \% \text { RDG or } \\
\pm 0.01 \mathrm{NTU}^{2}\end{array}$ \\
\hline $\begin{array}{l}\text { Backpressure } \\
\text { Fwd-Pressure }\end{array}$ & Steel rule & N/A & $0-6$ in & $\pm 1 / 128$ in $^{3}$ \\
\hline Backpressure & $\begin{array}{l}\text { Hand-held } \\
\text { Multimeter }\end{array}$ & N/A & N/A & N/A \\
\hline $\begin{array}{l}\text { Backpressure } \\
\text { Fwd-Pressure }\end{array}$ & Vernier Caliper & N/A & $0-6$ in & \pm 0.001 in \\
\hline
\end{tabular}

Notes: 1. Rotameter not calibrated. The tolerance is from vendor specifications (Omega FLD112).

2. Turbidity meter calibrated before each use with vendor supplied standards. The tolerance is from vendor specifications (HF Scientific, Micro 100 Turbidimeter). NTU = Nephelometric Turbidity Unit.

3. One-half of the least discernible increment (1/64 inch).

\subsection{Simulated Sludge}

The simulant used for the forward-pressure testing was SRS Tank 8F simulated sludge. The simulated sludge was based on the recipe in report WSRC-TR -2009-00045 [4] and contained no Resource Conservation and Recovery Act (RCRA) metals (barium, chromium lead) nor any halide salts (sodium chloride, sodium fluoride and sodium iodide). The expected content and properties of the simulated sludge are listed in Table 2-2 [5].

\section{Table 2-2: Expected Anion/Cation Content of Sludge Feed Simulants}

\begin{tabular}{|l|l|}
\hline Component & Concentration (wt \% dry) \\
\hline Cations & 9.59 \\
\hline Aluminum, $\mathrm{Al}$ & 2.11 \\
\hline Calcium, $\mathrm{Ca}$ & 0.13 \\
\hline Copper, $\mathrm{Cu}$ & 24.34 \\
\hline Iron, $\mathrm{Fe}$ & 0.005 \\
\hline Potassium, $\mathrm{K}$ & 0.12 \\
\hline Magnesium, $\mathrm{Mg}$ & 2.73 \\
\hline Manganese, $\mathrm{Mn}$ & 7.20 \\
\hline Sodium, $\mathrm{Na}$ & 2.79 \\
\hline Nickel, $\mathrm{Ni}$ & 0.76 \\
\hline Silicon, $\mathrm{Si}$ & 0.09 \\
\hline Strontium, $\mathrm{Sr}$ & 0.27 \\
\hline Zinc, $\mathrm{Zn}$ & \multicolumn{2}{|l|}{} \\
\hline Anions & 5.13 \\
\hline Carbonate, $\mathrm{CO}_{3}{ }^{2-}$ & 5.87 \\
\hline Nitrite, $\mathrm{NO}_{2}{ }^{-}$ &
\end{tabular}


SRNL-STI-2010-00790

Revision 0

\begin{tabular}{|l|l|}
\hline Component & Concentration (wt \% dry) \\
\hline Nitrate, $\mathrm{NO}_{3}{ }^{-}$ & 1.95 \\
\hline Total $\mathrm{Hydroxide}, \mathrm{OH}^{-}$ & 24.7 \\
\hline Oxide, $\mathrm{O}^{2-}$ & 11.4 \\
\hline Phosphate, $\mathrm{PO}_{4}{ }^{3-}$ & 0.13 \\
\hline Sulfate, $\mathrm{SO}_{4}{ }^{--}$ & 0.64 \\
\hline Properties & 1.1 \\
\hline Specific Gravity & 16.0 \\
\hline Total Solids, wt. \% & 3.0 \\
\hline Soluble Solids, wt. \% & $<0.05$ \\
\hline TOC (wet) &
\end{tabular}

The particle size distribution (PSD) for the simulated sludge is shown in Figure 2-5. The mean particle size was approximately 2.3 microns and approximately $3.8 \%$ of the particles were less than 1 micron [5].

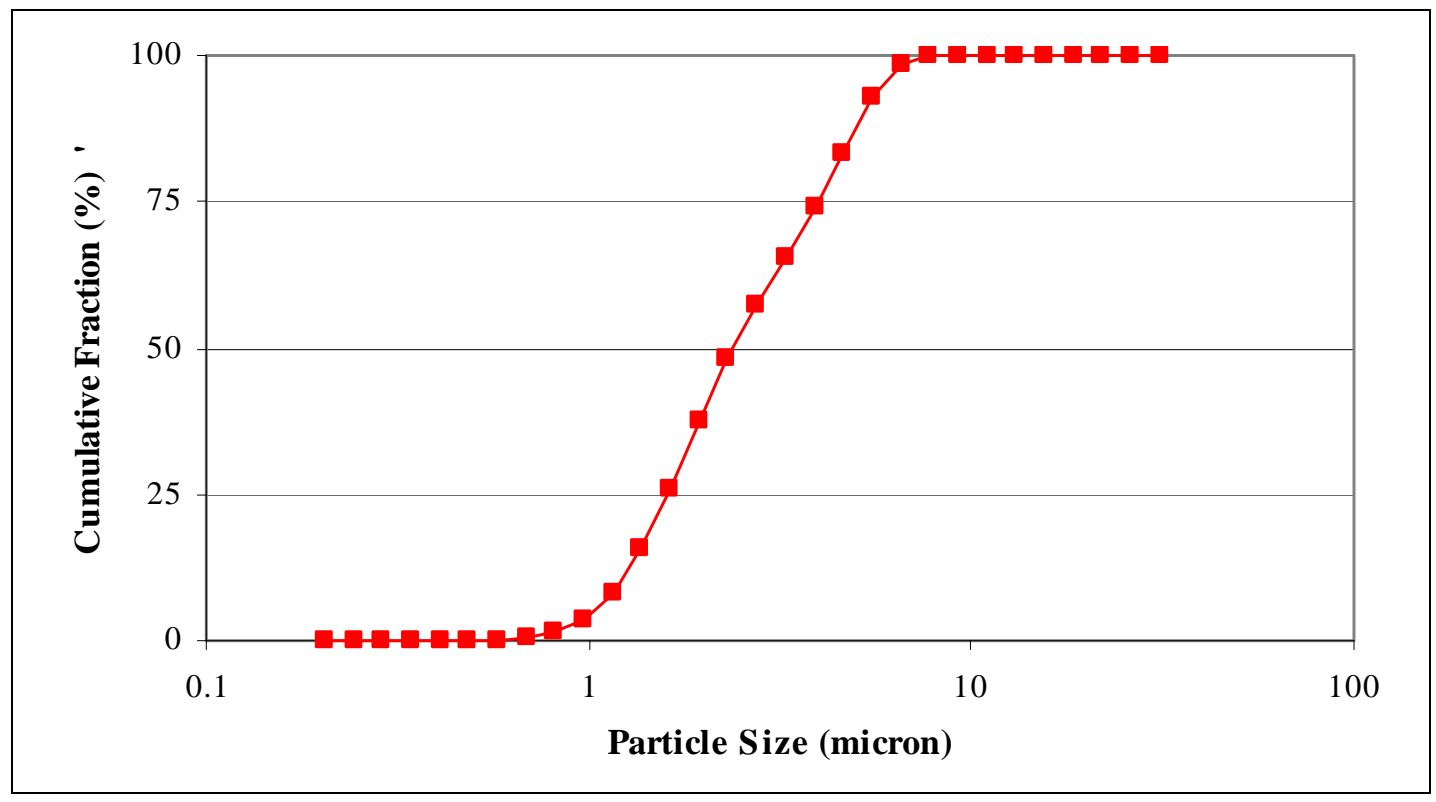

Figure 2-5: PSD of SRS Tank 8F Simulated Sludge

\subsection{Test Procedure}

The disks were pressurized in the backwards flow direction in increasing increments to determine the level where disk failure would occur. The increments were 5 psig and the maximum backpressure desired was 90 psig (150\% of the expected flush water pressure for the proposed SRS system). Failure was defined as the inability to filter effectively at the stated pore size. Each disk was pressurized separately but using different procedures.

The first disk was assembled with two turbulence promoters on either side and attached to the disk stand. The pressure line was attached and then the assembly was submerged in a 40 gallon clear acrylic tank. The disk assembly, with the stand, is shown in Figure 2-6.

Note in Figure 2-6 a black band around the OD of the hub fitting. This was electrical tape that (along with the Teflon spacers) electrically isolated the disk from the promoters. The intent was 
to measure the resistance between the disk and a promoter while submerged in the clear tank. The resistance was expected to notably change when the filter membrane expanded to contact the promoter. The resistance was measured by a hand-held multimeter. Unfortunately, the resistance measurement was unstable and did not provide reliable data.

The first disk was incrementally backpressured, stopping at each increment for a period of time to observe the air flow. An increased air bubble size or noticeable change in the bubble flow pattern would imply membrane failure. Multiple pictures and video were recorded during the backpressure test; some of the pictures are shown in this report and are included in the Laboratory Notebook [6]. The video or additional pictures are available upon request.

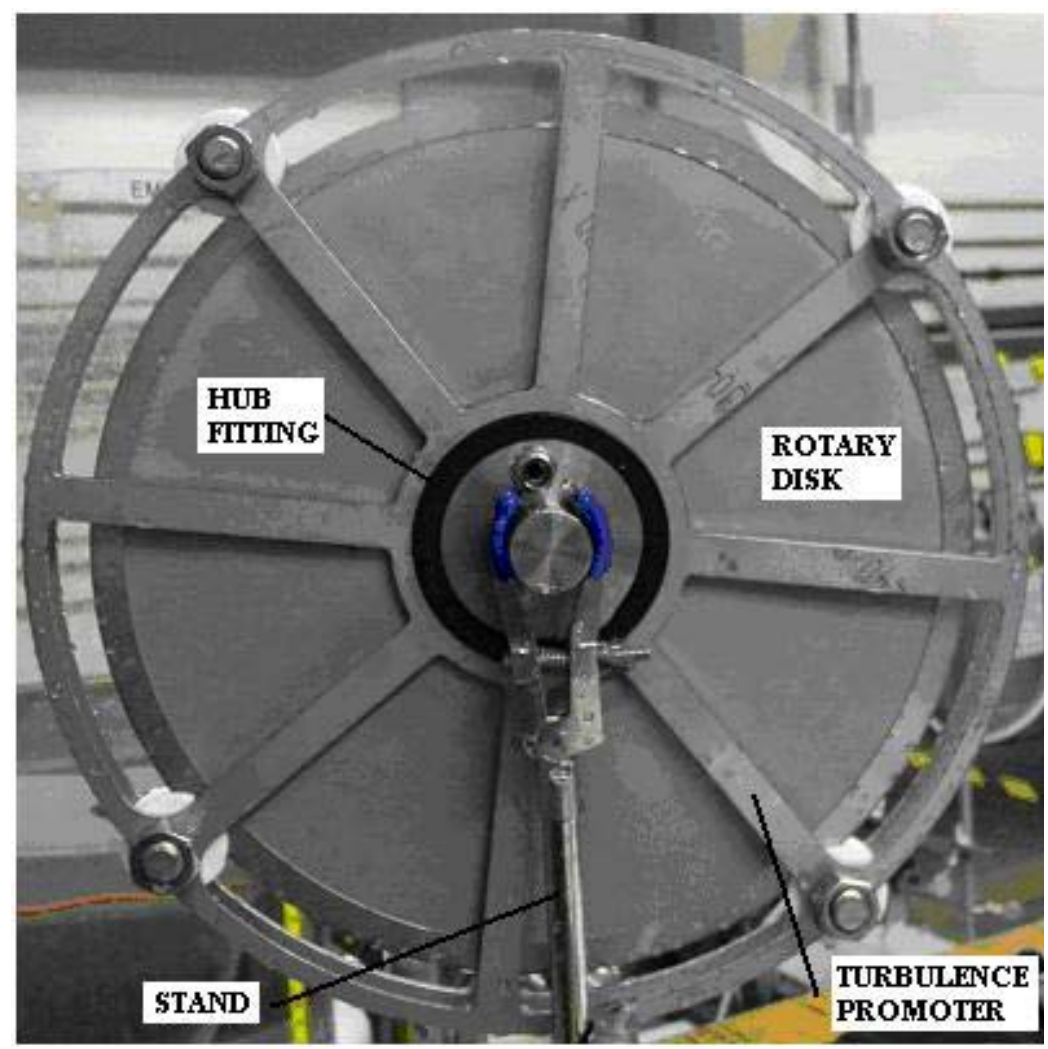

Figure 2-6: Disk Assembly for Backpressure Test

At the completion of the backpressure test the first disk was disconnected from the air supply, removed from the clear tank and inspected for damage. A forward-pressure test was conducted on the first disk to evaluate the effects of backpressure.

The second disk was assembled with two turbulence promoters on either side and attached to the disk stand. The pressure line was attached and then the assembly was submerged in a 40 gallon clear tank. The disk was backpressured to the first pressure increment (5 psig), the pressure was held for a period of time and then the air pressure was cut off. The air bubble flow pattern during the backpressure test was observed and, in addition, pictures and video were taken.

The disk assembly was removed from the tank and a forward-pressure test was conducted on the disk. A picture of the forward-pressure test equipment is shown in Figure 2-7. The same hub fitting was used for the forward-pressure test but the turbulence promoters were removed. The 
filtrate collection container was cleaned, the vacuum line was attached to the hub fitting and the disk was submerged in the tub of simulated sludge. Filtrate was first extracted to rinse the collection beaker then drawn for turbidity measurement. The filtrate was extracted by applying a slight vacuum to the disk (approximately 4 in $\mathrm{Hg}$ ), the magnitude of which was controlled by the vent valve. Approximately $100 \mathrm{ml}$ of filtrate was collected for the turbidity measurement.

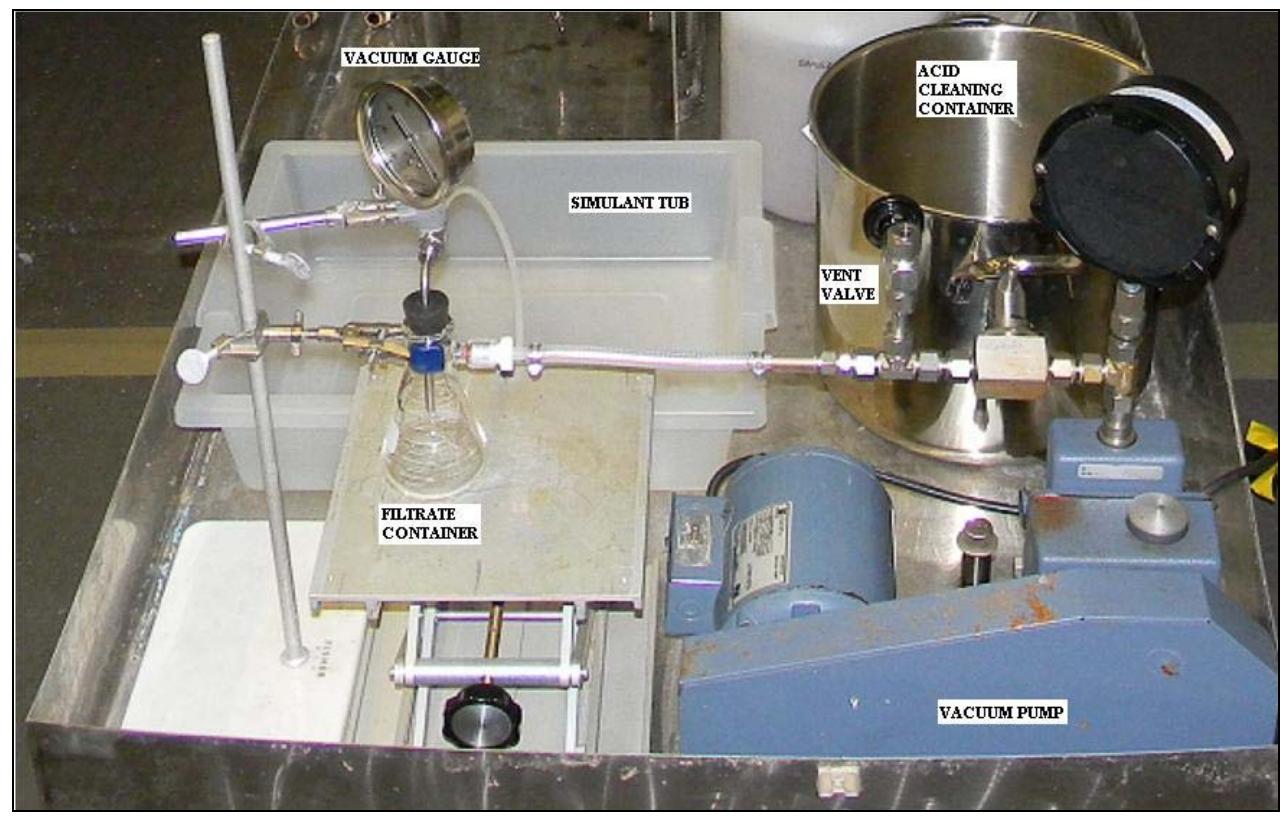

Figure 2-7: Forward-Pressure Test Equipment

Following the turbidity measurement the disk was cleaned and re-assembled. The disk was cleaned by first rinsing with DI water, wiping the surface with a wet paper towel to remove stubborn clumps of sludge and finally soaking in 1 molar nitric acid for an extended period (two or more hours). The process was then repeated at the next backpressure increment (+5 psig)

\subsection{Results}

\subsection{Testing Summary}

Both disks were subjected to backpressure and forward-pressure testing. The following discussion details the results of the testing. The filter membranes of both disks were permanently deformed during backpressure testing but retained the ability to effectively filter the simulated sludge. The deformation was evident as a bulge in the membrane that was uniform around the axis of rotation and mostly at the hub, tapering towards the perimeter of the disk, where there was no deformation.

The amount backpressure that caused the deformation was inconsistent between the two disks. The first disk showed permanent deformation after 45 psig. Disk 1 was eventually backpressured to 75 psig with little additional deformation. The deformation was not great enough to allow contact with the stationary turbulence promoters. Disk 2 deformed at 5 psig and the deformation appeared to contact the promoters. For Disk 2 the amount of deformation was significant because it would have caused membrane failure during rotational operation due to impact with the stationary turbulence promoters. The turbidity readings of filtrate drawn from both disks 
remained relatively constant from before and after the deformation, indicating that the ability of the RMF to filter solids was not affected.

\subsection{Disk 1}

\subsubsection{Backpressure Test}

The Disk 1 was backpressured from 5 to 40 psig in 5 psig increments on one day and from 20 to 75 psig on the following day. The increments on the second day of testing were 10 psig from 20 to 40 psig then 5 psig from 40 to 75 psig. The hold time at each increment varied from 5 to 10 minutes on the first day and 4 to 6 minutes on the second day. The pressure values do not include the DI water pressure head (the water height was 23 inches, the top of disk was 19 inches) nor the line losses from the pressure gauge to the membranes. The disk was removed from the tank and inspected at the end of each day.

Figure 3-1 shows a typical bubble pattern for Disk 1 during the backpressure test. The bubble flow pattern throughout each day of testing appeared uniform across both sides of the disk, however, at the higher pressures (above 30 psig) the features of the disk above the hub were obscured by the intense bubble flow. Regardless, any physical damage to the filter membrane was expected to be readily detected at both the lower and higher backpressures. Physical damage was not detected during the entire backpressure test of the first disk regardless of the bubble flow.

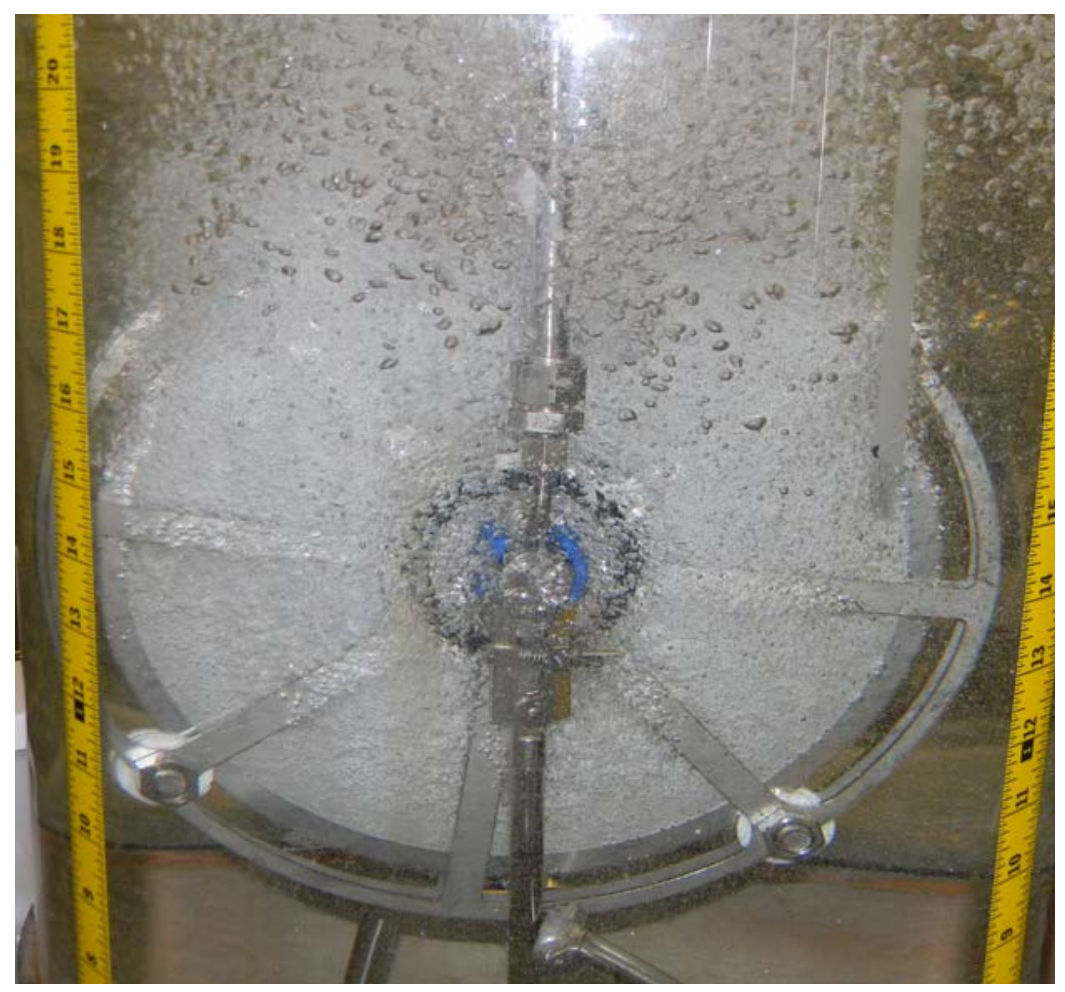

Figure 3-1: Disk 1 during the Backpressure Test

The inspection at the end of the first day revealed some deformation of the filter membranes of both sides in the form of a permanent bulge near the hub fitting. Figure 3-2 shows the disk assembly in the stand. Note the diminishing gap between the side of the promoter spoke and its 
reflection at the 6 o'clock position. The gap was 0.05 inches at the closest point and 0.125 inches at the OD of the membrane.

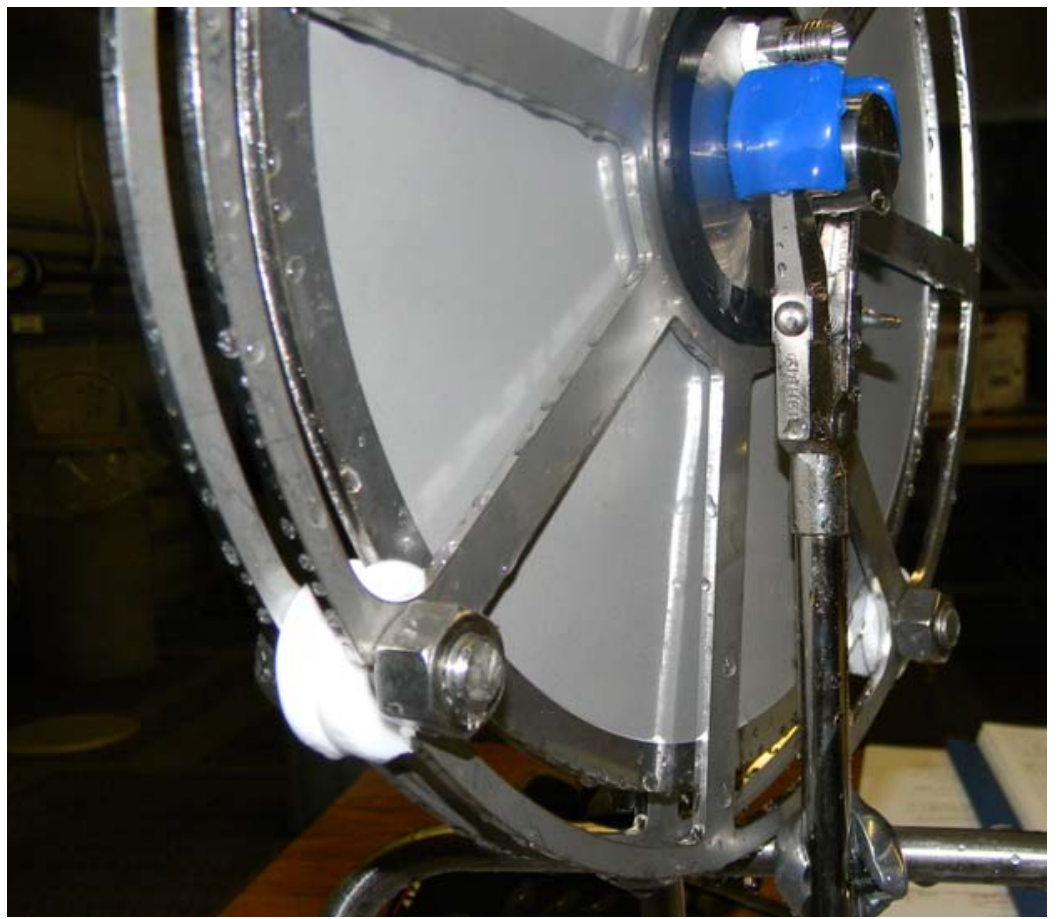

Figure 3-2: Disk 1 After 40 psig Backpressure

The inspection at the end of the second day revealed deformation, however, the amount of deformation did not appear to have increased. The gaps between the promoter spokes and the membrane measured at the end of the second day were comparable to the gaps at the end of the first day. Figure 3-3 shows the deformation of the first disk at the end of the second day. The first photo is the assembly, highlighting the diminishing gap from the OD to the hub between the membrane and promoter spoke. The second photo is the hub of the disk showing the extent of deformation around the hub fitting. When a flat-edge was laid across the bulges the maximum height of the flat-edge from the core surface was 0.160 inches (measured on both sides of disk).

Backpressure testing of the first disk was stopped at 75 psig because the administrative limit of 90 psig was reached upstream of the air drier (15 psig loss in the air drier at 90 psig supply). A greater administrative limit was not pursued due to the amount of deformation. 


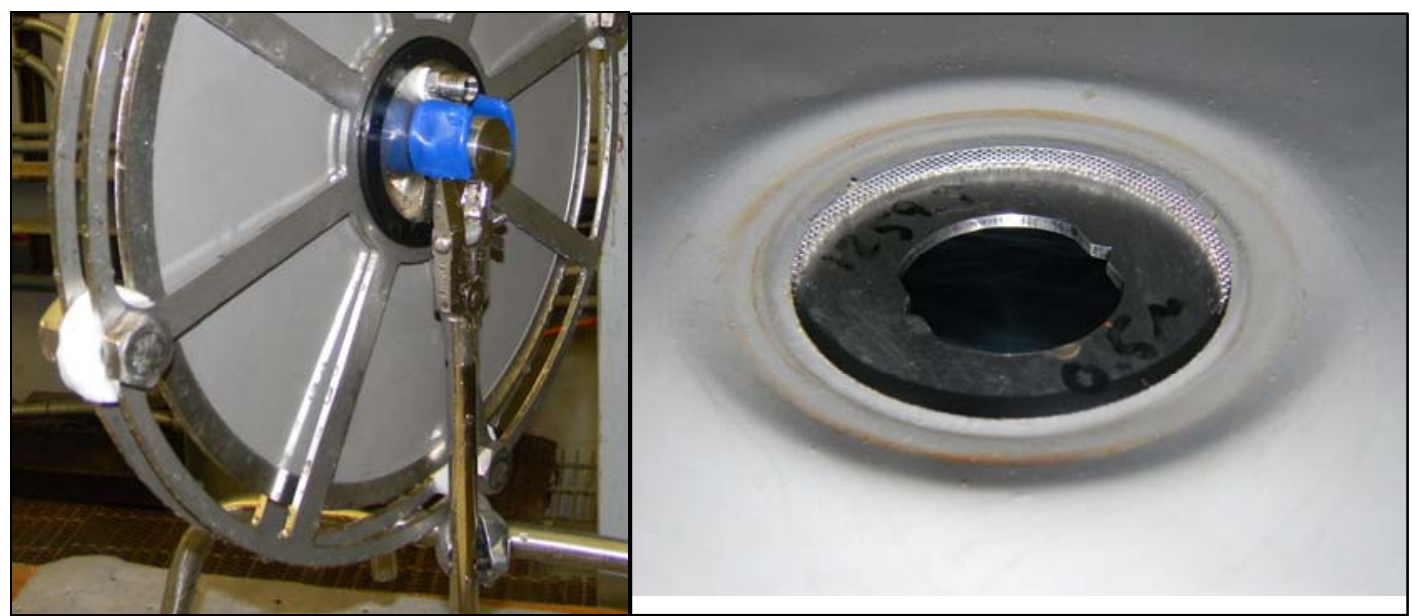

Figure 3-3: Disk 1 After 75 psig Backpressure

\subsubsection{Forward-Pressure Test}

The Disk 1 was subjected to a forward-pressure test after the backpressure tests. Filtrate was drawn with relative ease at a vacuum of $\sim 4$ in $\mathrm{Hg}$ (typical pressure drop across the 25 disk filter during normal operation is 40 psid). The turbidity of the filtrate was 1.5 NTU. The pre-test turbidity from Disk 1 was not measured; however, the pre-test turbidity of the second disk was measured and provided good comparison to the first disk post-test turbidity. The pre-test turbidity of Disk 2 was 10.9 NTU. The relative similarity of the values implied that the deformation did not adversely affect the integrity of the RMF.

\subsection{Disk 2}

\subsubsection{Backpressure Test}

The Disk 2 was backpressured to 5 psig for 10 minutes then removed from the tank for inspection. The bubble flow pattern appeared uniform throughout the test. Upon inspection it was seen that the filter membranes on both sides had permanently deformed to the extent where one appeared to contact a spoke of the turbulence promoters. Figure 3-4 shows the deformation of the second disk after the initial backpressure test of 5 psig. The first photo is the disk assembly showing the gap between the membrane and promoter spoke. The second photo shows the extent of deformation near the hub fitting. The smallest gap between the membrane and spoke was 0.008 inches. The gap at the OD of the membrane was 0.125 inches. The backpressure testing of the second disk was not continued since it appeared that one membrane had deformed to the turbulence promoter in the 5 psig test, implying membrane failure during rotational operation. When a flat-edge was laid across the bulges the maximum height of the flat-edge from the core surface was 0.230 inches (measured on both sides of disk). 


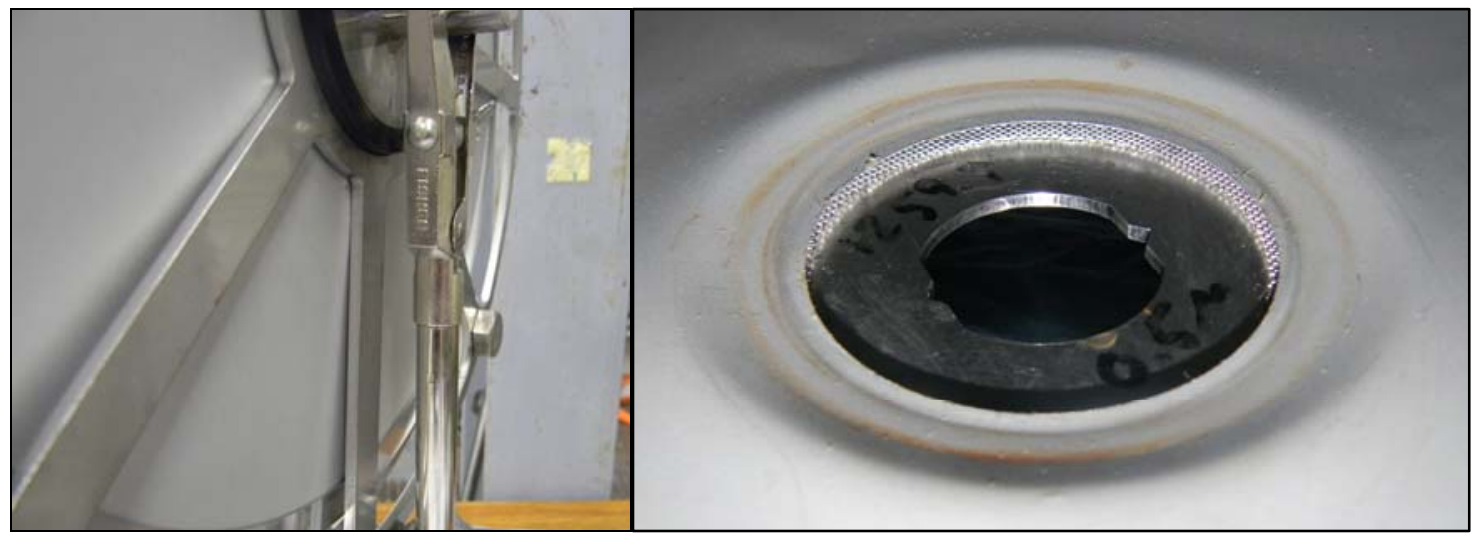

Figure 3-4: Deformation of Disk 2 Membrane

\subsubsection{Forward-Pressure Test}

A forward-pressure test was conducted on Disk 2 following the backpressure test. Filtrate was drawn with relative ease at a vacuum of $\sim 4$ in Hg. The turbidity of the filtrate was 2.2 NTU. The pre-test filtrate was 10.9 NTU. The relative similarity of the values implies that the deformation did not significantly adversely affect the efficiency of the RMF.

Figure 3-5 shows the filtrate from the second disk along with vials of the turbidity standards used to calibrate the turbidity meter. The turbidity values of the standards, from left to right, are 0.02 , 10.0 and 1000 NTU. The filtrate appears clear with some yellowish coloring. Referencing the PSD chart in Figure 2-5, there is a negligible amount of particles below the nominal pore size of the RMF (0.5 micron) and only $3.8 \%$ of the particles less than 1 micron. The slight coloration of the filtrate can be attributed to dissolved solids and conceivably the small percentage of particles less than 0.5 micron in the simulated sludge that may have passed through the filter (reference Figure 3-5).

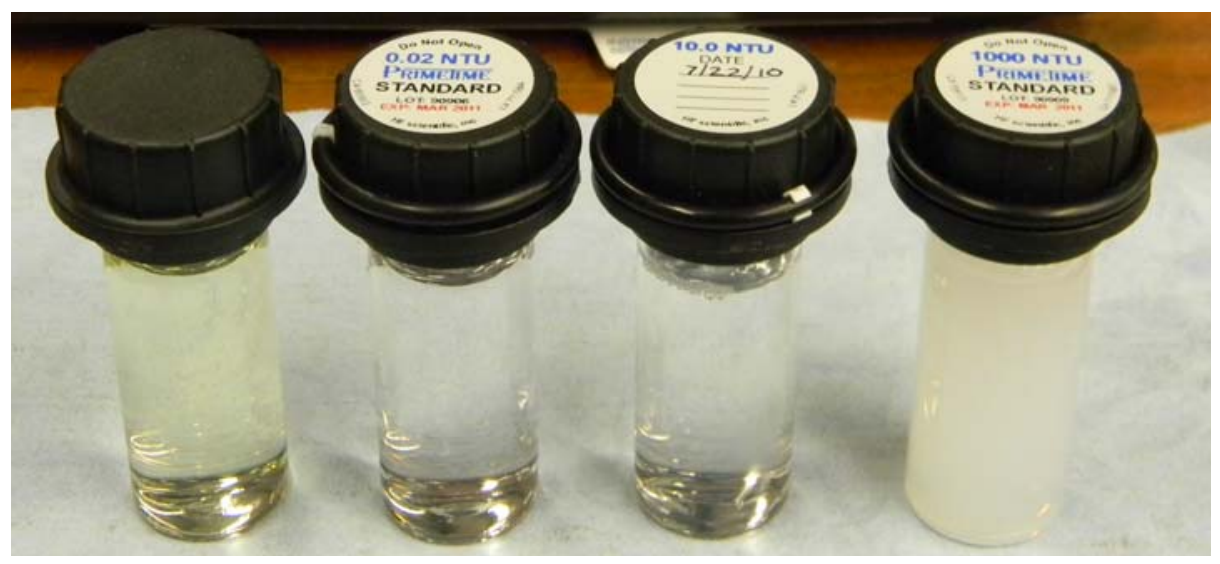

Figure 3-5: Vials of Filtrate (left) and Turbidity Standards (0.02, 10.0 \& 1000 NTU) 


\subsection{General Comments}

\subsubsection{Filter Breakthrough}

The turbidity values after backpressure testing for Disk 1 and Disk 2 (1.5 NTU and 2.2 NTU, respectively) were lower than the pre-test values of Disk 2 (10.9 NTU). There are two possible reasons for the apparent decrease in post-test turbidity. First, the pre-test vial may not have been thoroughly cleaned prior to measurement. Second, the efficiency of the membranes may have improved after the initial forward-pressure tests, due to solids loading. Experience with the RMF filters has shown that the efficiency increases as material is filtered (after the filter is "broken in"). Solids partially fill the filter pores essentially decreasing the filter pore size.

\subsubsection{Membrane Deformation}

The extent of the membrane deformation is shown in Figure 3-3 (Disk 1) and Figure 3-4 (Disk 2). The shape and location of the deformation was similar between the two disks but the pressure at which the deformation occurred and the extent of the deformation was not. Wrinkles or slack in the membrane may have contributed to the differing amounts of deformation.

Each side of the RMF is constructed by first laying the pre-cut doughnut of membrane material on top of a pre-cut doughnut of large-mesh screen on top of the solid core. A thin stainless steel ring, approximately 0.4 inches wide and slightly larger than the OD of the disk, is seal welded around the OD circumference, which bonds the membrane and core together. The membrane is bonded to the core at the OD only. The membrane lies loosely on the screen and is not stretched prior to welding. The membrane is typically flat but, in some assemblies, wrinkles or other contour irregularities have been noted. The presence of wrinkles, or slack in the membrane, may provide more "give" during deformation. Figure 3-6 shows both sides of the second disk prior to the backpressure test. Wrinkles and other irregularities can be seen on both sides of the disk; more so in the second photo, at about the 4 o'clock position at the OD. Pre-test pictures of the Disk 1 are not available for comparison.

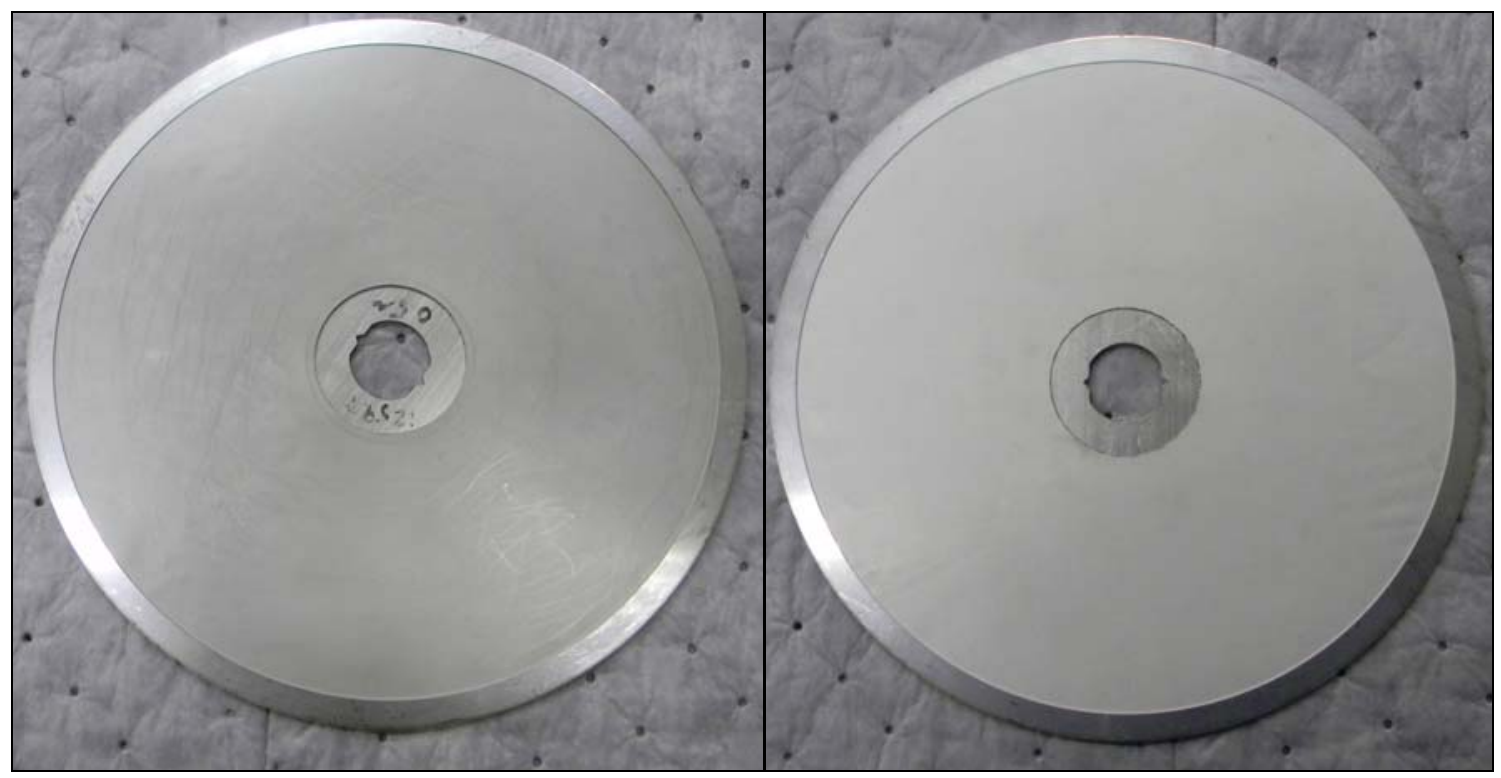

Figure 3-6: Wrinkles in the Front and Back Membranes of Disk 2 
There may be other contributing factors for the greater deformation such as the torque applied to the hub fitting during assembly. The torque was not measured but may have been less for the disk that had more deformation. A reduced torque might allow material to slide under the o-ring during deformation providing more material for the deformation.

\subsection{Conclusions and Recommendations}

The following conclusions were made from the backpressure testing of two stainless steel RMF disks with Pall Corporation PMM050 membranes.

1. The membranes did not tear, burst or otherwise lose physical integrity during the application of backpressure of up to 75 psi.

2. Backpressure caused permanent deformation of the membranes of both disks. In one case, deformation occurred at or below 5 psig backpressure. Initial deformation in the other disk occurred somewhere below 40 psig.

3. The greatest deformation occurred towards the center of the disk, adjacent to the hub.

4. The amount of deformation was different between the two disks tested, which is most likely due to a different amount of slack in the membrane prior to fabrication.

5. In one of the two disks tested the membrane appeared to deform to an extent where contact was made with a spoke of a turbulence promoter. Contact with the stationary turbulence promoter during rotational operation would cause membrane failure.

6. There was no loss in the filtration efficiency of both disks following deformation as measured by filtrate turbidity during stationary conditions.

There are two general solutions to the issue of membrane deformation. The first solution is to make the filter membrane less susceptible to deformation. This may accomplished in several ways, some being;

- Use a stiffer membrane,

- Affix the Pall membrane to the screen,

- Affix the Pall membrane and the screen to the disk core.

The second solution is to eliminate the possibility of backpressure through engineering controls and administrated measures.

\subsection{References}

1. M. R. Poirier, D. T. Herman, D. B. Stefanko, S. D. Fink, "Testing of a Rotary Microfilter to Support Hanford Applications”, WSRC-STI-2008-00339, rev. 0, June 26, 2008.

2. B. E. Reed, W. Lin, R, Viadero Jr., "Treatment of a Concentrated Oily Waste Using the Spintek Rotary Ultrafiltration System”, 1997 Conference Proceedings, Advances in Filtration and Separation Technology Volume 11, April 29- May 4, Minneapolis, MN.

3. D. T. Herman, M. R. Poirier and S. D. Fink, “Task Technical and Quality Assurance Plan for the Backpressure Allowable for Rotary Microfilter Disks”, SRNL-TR-2009-001435, rev. 0, March 27, 2009.

4. M. R. Poirier, "Recipe for Simulated Tank 8F Sludge Containing No RCRA Metals or Halides, WSRC-TR-2005-00045, rev. 0, January 14, 2005.

5. D. T. Herman, "Properties of the Tank 8F Simulant", SRNL-STI-2010-00020, rev. 0, January 2010. 
SRNL-STI-2010-00790

Revision 0

6. D. T. Herman, M. D. Fowley, Laboratory Notebook WSRC-NB-2006-00038, "Filter Testing”, May 2010 - January 2011. 


\section{Distribution:}

F. M. Pennebaker, 773-A

B. J. Giddings, 786-5A

S. L. Marra, 773-A

M. D. Fowley, 786-5A

D. T. Herman, 735-11A

M. R. Poirier, 773-42A

A. B. Barnes, 999-W

D.A. Crowley, 773-43A

S. D. Fink, 773-A

C. C. Herman, 999-W

W. R. Wilmarth, 773-A

P. C. Suggs, 704-S

M. T. Keefer, 766-H

T. H. Huff, 773-66A

M. A. Rios-Armstrong, 773-66A

R. E. Edwards, 773-67A

D. M. Patel, 773-66A 